\title{
The universality of symbolic representation for reading in Asian and alphabetic languages
}

\section{Citation}

BIALYSTOK, ELLEN, and GIGI LUK. 2007. "The universality of symbolic representation for reading in Asian and alphabetic languages." Bilingualism: Language and Cognition 10 (02) (July 4): 121. doi:10.1017/S136672890700288X. http://dx.doi.org/10.1017/S136672890700288X.

\section{Published Version}

doi:10.1017/S136672890700288X

\section{Permanent link}

http://nrs.harvard.edu/urn-3:HUL.InstRepos:11384945

\section{Terms of Use}

This article was downloaded from Harvard University's DASH repository, and is made available under the terms and conditions applicable to Other Posted Material, as set forth at http:// nrs.harvard.edu/urn-3:HUL.InstRepos:dash.current.terms-of-use\#LAA

\section{Share Your Story}

The Harvard community has made this article openly available.

Please share how this access benefits you. Submit a story.

\section{Accessibility}




\section{Bilingualism: Language and Cognition}

http://journals.cambridge.org/BIL

Additional services for Bilingualism: Language and Cognition:

Email alerts: Click here

Subscriptions: Click here

Commercial reprints: Click here

Terms of use : $\underline{\text { Click here }}$

\section{The universality of symbolic representation for reading in Asian and alphabetic languages}

ELLEN BIALYSTOK and GIGI LUK

Bilingualism: Language and Cognition / Volume 10 / Issue 02 / July 2007, pp 121 - 129

DOI: 10.1017/S136672890700288X, Published online: 04 July 2007

Link to this article: http://journals.cambridge.org/abstract S136672890700288X

How to cite this article:

ELLEN BIALYSTOK and GIGI LUK (2007). The universality of symbolic representation for reading in Asian and alphabetic languages. Bilingualism: Language and Cognition, 10, pp 121-129 doi:10.1017/S136672890700288X

Request Permissions : $\underline{\text { Click here }}$ 


\title{
The universality of symbolic representation for reading in ELLEN BIALYSTOK GIGI LUK Asian and alphabetic languages*
}

\begin{abstract}
Neuroimaging studies of reading have identified unique patterns of activation for individuals reading in alphabetic and Asian languages, suggesting the involvement of different processes in each. The present study investigates the extent to which a cognitive prerequisite for reading, the understanding of the symbolic function of print, is common to children learning to read in these two different systems. Four-year-old children in Hong Kong learning to read in Cantonese and children in Canada learning to read in English are compared for their understanding of this concept by means of the moving word task. Children in both settings performed the same on the task, indicating similar levels of progress in spite of experience with very different writing systems. In addition, the children in Hong Kong benefited from the structural similarity between certain iconic characters and their referents, making these items easier than arbitrary characters. These results point to an important cognitive universal in the development of literacy for all children that is the foundation for skilled reading that later becomes diverse and specialized.
\end{abstract}

The stunning increase in the sophistication of neuroscience techniques in psychology has been accompanied by an equally impressive increase in the complexity of the questions to which these techniques are applied. The cognitive processes underlying skilled reading are one such beneficiary of these methods. Moreover, studies comparing individuals reading in different languages, and especially in languages that are coded through different writing systems, have provided a window on the connections between the linguistic and cognitive skills involved in reading and have contributed to our understanding of how these interactions change with the demands of different languages and writing systems.

One reliable method for investigating potential differences in the neural networks underlying reading in different languages is to study bilinguals, controlling for individual differences in ability or strategy. Studies of brain imaging using such participants have shown that there are both common and unique networks activated when reading languages represented by different writing systems (e.g., Tan et al., 2001; Tan et al., 2003; Bolger, Perfetti and Schneider, 2005). The bilinguals in these studies were primarily learners of English who already knew a non-alphabetic native language, namely, Chinese, Japanese, or Korean. This research has focused on Asian languages in combination with

* This research was funded by a grant from the Natural Sciences and Engineering Research Council of Canada (NSERC) to the first author.
English because the obvious differences between the writing systems invite the possibility that the cognitive processes involved in reading them are also different. Whereas English is represented alphabetically by coding symbols for individual phonemes, Asian languages code either syllables or morphemes as the unit of writing (Coulmas, 1991). This research has shown that bilingual adults reading in both English and an Asian language show different patterns for each language, although some common areas are activated as well (for Japanese-English bilinguals, see Tatsuno and Sakai, 2005; for ChineseEnglish bilinguals, see Xue et al., 2004). Liu and Perfetti (2003) found that Chinese-English bilinguals had more bilateral activation when reading Chinese characters than when reading English words. Tan et al. (2003) reported that when Chinese-English bilinguals judged whether two English words rhymed, they had stronger activation in the left middle frontal and posterior parietal gyri than did their English monolingual peers. These results, however, could reflect either processing differences attributable to bilingualism or to the specific characteristics of the Chinese writing system. A study by Chen et al. (2002) supports the interpretation that the important factor is the writing system: Chinese readers activated the inferior parietal cortex for pinyin (an alphabetic system used to represent sounds in Chinese) but had stronger activation in the fusiform gyrus when processing characters.

These results are difficult to reconcile with research on children's acquisition of literacy in which commonality

Address for correspondence:

Ellen Bialystok, Department of Psychology, York University, 4700 Keele Street, Toronto, Ontario, M3J 1P3, Canada

E-mail: ellenb@yorku.ca 
across languages and writing systems seems to be more significant than specialization. Studies have repeatedly shown that the progress of bilingual children learning to read in their two languages is strongly related (Geva, Wade-Woolley and Shany, 1993; Geva and Siegel, 2000; D'Angiulli, Siegel and Serra, 2001). These correlations suggest that reading is built on a common foundation it is primarily a cognitive skill into which linguistic knowledge is supplied. However, for children learning to read in English and an Asian language, the results have been different. In three studies investigating bilingual 6-year-olds learning to read in both languages, children learning to read two alphabetic languages revealed the familiar correlation between progress in both languages (Bialystok, Luk and Kwan, 2005), but children learning to read English and Chinese showed no correlation in their progress for these two languages (Bialystok, Luk and Kwan, 2005; Bialystok, McBride-Chang and Luk, 2005; Bialystok and Luk, in press), a result found by others (Gottardo et al., 2001). This dissociation supports the results of the neuroimaging studies and leads to an interpretation of distinct processing for reading in these different writing systems. It is reasonable to assume that processes based on different functional networks will develop independently. At what point, however, do reading processes in an alphabetic and an Asian language diverge and come to rely on different sets of cognitive processes?

In spite of the involvement of different brain regions in skilled readers and the independent progress in acquisition for bilingual children, reading in English and reading in Chinese still share considerable commonality. Reading in both languages depends on phonological awareness (Ho and Bryant, 1997; Chan et al., 2006; Chow, McBride-Chang and Burgess, 2005 for Chinese reading; McBride-Chang, 1995 for English reading); morphological sensitivity (McBride-Chang et al., 2003 for Chinese reading; Nunes, Bryant and Bindman 1997; Nunes, Bryant and Olsson, 2003 for English reading) and vocabulary level (Wang, Cheng and Chen, 2006 for Chinese-English biliteracy). Moreover, the neuroimaging literature also points to commonly activated areas for reading in these two systems. For example, two separate meta-analyses on neuroimaging studies comparing character and alphabetic processing showed that a common cortical network was employed across languages and writing systems, although specific localization within the network varied across writing systems (Bolger et al., 2005; Tan et al., 2005). Pu et al. (2001) also observed similar hemodynamic response curves in the left inferior to middle frontal lobe when Chinese-English bilinguals generated verbs in Chinese and English. The question, therefore, is to determine what common preparation allows children to read in whatever system is ultimately required for literacy and when the specialization required for different systems begins to appear.
One of the crucial precursors to reading is the understanding of the system of print and how it symbolically encodes spoken language. This insight requires that children understand that representations can be symbolic (i.e., A STANDS FOR B, as opposed to A IS A B) and that they possess sufficient control of attention to switch between the components of this relationship in the context of other distracting cues on the page, such as pictures (Bialystok and Martin, 2003). This symbolic insight comes after they have learned the formal constituents of the writing system, such as letters for an alphabetic language; until it is achieved, children are unable to read.

This need to understand concepts of print is universal across writing systems and is a prerequisite for reading in any system. Regardless of the way a spoken language is encoded in print, children need to understand that the purpose of the print is to provide an invariant representation that can be transformed back into the spoken forms through a reliable set of rules or principles. This insight is equally important whether the symbols on the page stand for sounds, syllables, or morphemes. The nature of the writing system, however, might make that insight more or less easy to achieve. Do children learning to read in different languages, based on different writing systems, and engaging different neural networks, acquire this insight differently?

Bialystok and colleagues have investigated this question by using the moving word task (Bialystok, 1991). Children are selected for study if they can identify the forms of print (e.g., letters for children learning to read in English) and write their own name to demonstrate familiarity with the production and meaning of print, but cannot yet read independently. In the basic paradigm, children are shown two pictures and the experimenter and the child name the pictures and have a brief conversation about them. After this, the pictures are never mentioned or explicitly indicated. The experimenter brings out a card that contains the name for one of the pictures, tells the child the word on the card, and places it under the pictures it names. The child is asked the introductory question, "What does this card say?"; this question will be asked three times during the procedure. After the first response, an "accident" from some stuffed toy or other distraction moves the card so it is under the other picture. The experimenter comments on the mess and asks the question for the second time, called the incongruent question. Finally, the experimenter notes that the card is not in the original position and proceeds to return it to be under the named picture. The question is then asked for the third time, called the congruent question. The important response is to the incongruent question, when the card is under the picture it does not name. If the child understands that the word on the card is determined by the print, and the print has clearly not changed (being in 
full view the whole time), and also that the picture does not contribute to the meaning of the word, then the child will answer the incongruent question correctly. Children who are not confident about how print derives its meaning or believe that the picture has some role in attributing meaning to the print will change their answer to this question. The effectiveness of the moving word task to assess these concepts was replicated by Robinson and colleagues by using both standard procedures (Collins and Robinson, 2005) and other variations (Apperly and Robinson, 2003; Collins and Robinson, 2005). Moreover, in several studies, we have shown that bilingual children answer the incongruent question correctly at an earlier age than monolinguals (Bialystok, 1997, 1999; Bialystok, Shenfield and Codd, 2000; Bialystok and Senman, 2004).

This research has identified the concept of print as it is assessed in the moving word task to be one of the prerequisites for reading. Moreover, the insight transfers across languages; it is not necessary to relearn the symbolic principle even if the two languages use completely different writing systems. Thus, bilingual children exposed to print in two languages perform the same on the moving word task in both of them, regardless of whether the languages are both alphabetic, such as English and Hebrew (Bialystok et al., 2000) or based on different principles, such as English and Chinese (Bialystok, 1997). Even with no correlation in children's early progress in reading in English and Chinese, bilingual children learning to read in both languages perform exactly the same on versions of the moving word task assessing their understanding of print in both languages.

Just as the differences in neural activation for EnglishChinese bilinguals described above could be logically attributed either to the bilingualism of the participants or to differences between the writing systems, so too the similarity in performance on the moving word task for English-Chinese bilinguals may reflect either a consequence of bilingualism or a true commonality in learning about a writing systems. It is possible, for example, that bilingual children achieve the insight about print and then transfer it to the other language, accounting for the correlation in performance. This explanation fits well with the observation that bilingual children learn to solve the task reliably earlier than monolingual children; they profit from the extra experience or additional evidence encountered in two writing systems. However, given that reading in English and in Chinese have been shown to engage different neural circuitry, it is not necessarily the case that children learning to read in each of these languages have the same need to establish this concept of print as a precursor to reading.

The nature of the Chinese writing system may make the symbolic insight about print easier to master because meaning is more directly accessible in a character system than in an alphabetic one. For children learning to read
English, the sounds encoded in the print need to be reassembled into words, a process that is difficult because the sounds themselves, and the letters that represent them, have no individual meaning. In Chinese, in contrast, some of the morphemic characters can be directly encoded into meaningful units. Therefore, it is possible that children understand immediately how print refers to meaning and will not make the error in the incongruent question. This facilitation might be especially apparent in iconic characters that are structurally indicative of the words they represent. Such characters may be interpreted more pictorially than arbitrary characters whose structure provides no indication of meaning. In a study examining the ability of monolingual English-speaking 4-year-olds to understand the symbolic function of various notations, pictorial line drawings were easily recognized by all children as being symbolic representations for meanings, but notations composed of letters (words) or numbers led to errors on the incongruent question (Bialystok, 2000). Therefore, the symbolic function of print may be an easier insight for children learning to read Chinese, bypassing an essential prerequisite for acquiring literacy in a language with an alphabetic system. Such a result would reinforce the uniqueness of Chinese reading found in studies of brain imaging. The present study examined this possibility by studying monolingual children acquiring concepts of print in either English or Chinese.

\section{Method}

\section{Participants}

Twenty-three English-speaking children from Canada (8 females) and 36 Cantonese-speaking children from Hong Kong (31 females) who were attending junior kindergarten participated in the study. The mean ages of the Canadian and Hong Kong children were $49.0(s d=5.2)$ and 49.8 $(s d=2.8)$ months, respectively. All the children in Hong Kong were monolingual speakers of Cantonese and all the children in Canada were monolingual speakers of English. The children had basic knowledge of reading but could not read independently. Children from Hong Kong and Canada were recruited from middle-class areas. None of the schools in either Hong Kong or Canada provided any financial assistance to the children. To participate in the study, children needed to demonstrate their knowledge of written forms by recognizing their own names in print as well as at least three consonant letters for children in Canada or number characters for children in Hong Kong. In addition, they all failed to read the four experimental items used in the moving word task.

\section{Tasks and design}

Parental consent was obtained prior to testing and all the sessions were carried out in the kindergarten that 
the children attended. The same bilingual experimenter (GL) tested all the children in both settings, speaking only English to the children in Canada and Cantonese to the children in Hong Kong. In addition to the moving word task, three background measures were included to ensure comparability of the children in the two language groups. These were the Peabody Picture Vocabulary Test (PPVT), the print awareness test, and the catdog inhibition task. The PPVT was included because of the importance of oral vocabulary in establishing concepts of print (Adams, 1990), and the print awareness and inhibition tasks were included because they both predict performance on the moving word task (Bialystok and Martin, 2003). Therefore, differences in any of these three measures could lead to performance differences in the moving word task even without actual differences in understanding this concept, making it essential that they are controlled. Each child was given one of the four presentations of the moving word task alternating with each of the three background measures, presented in a fixed order. The session was conducted in a casual and playful atmosphere.

\section{Peabody Picture Vocabulary Task (3rd edn., PPVT-III)} The PPVT-III (Dunn and Dunn, 1997) is a standardized test for receptive vocabulary. Each child was presented with a page of four pictures while the experimenter says a word. There are two versions that are of similar difficulty level, A and B. The Canadian children were given Form $\mathrm{A}$ in English. Form B of the task was translated by a native Cantonese speaker into Chinese and the translated version of Form B was given to the Hong Kong children. The basal set is established when the child has one or no errors in a set of 12 items, and ceiling is obtained when the child has eight or more errors in a set. Raw scores of both the English and Cantonese versions were obtained by subtracting the number of errors between the basal and ceiling sets from the last item administered. The resulting raw scores were transformed to standardized scores based on norm tables corrected for age. Therefore, the standardized scores of the Hong Kong children were only approximate standardizations.

\section{Print awareness task}

The task assesses children's awareness of the written forms of the language that they speak. Each child was given a toy figure called "John" and was told that John spoke the same language as the child (English for Canadian children and Cantonese for Hong Kong children). Children were then shown a display consisting of three identical faces, each speaking a different language, as indicated by text written in a bubble coming from the speaker's mouth. The three languages were Russian, Japanese and either English or Chinese for the Canadian and Hong Kong children, respectively. The child was asked whom John should talk to among the three people speaking different languages. For the Canadian children, a score of 2 was given if children chose English, 1 if they chose Russian, and 0 if they chose Japanese. For Hong Kong children, a score of 2 was given if the child chose Chinese, 1 if they chose Japanese, and 0 if they chose Russian. In each case, the language awarded a score of 1 is more similar in appearance because of shared writing system features than the language for which the score is 0 . For example, although English and Russian use different scripts consisting of different letters, both languages are alphabetic; similarly, Cantonese and Japanese are both represented by characters, even though the characters themselves are different. Three trials counterbalancing the position of the target languages (English or Chinese) were administered, yielding scores out of 6 .

\section{Cat-dog inhibition task}

This task is an adaptation of Gerstadt, Hong and Diamond's (1994) day-night Stroop task but uses pictures of a cat and dog instead of day and night. In addition, pictures of the cat and dog were presented simultaneously on a poster board, rather than sequentially on individual cards. On a large poster board, twelve dog and twelve cat stickers were presented along a path. There was a windmill at the beginning of the path and a house at the end, with trees, clouds, and a sun along the way. All the items except for the dog and cat stickers, that is, the beginning and end markers and the trees, clouds, and sun, were attached with Velcro tape. In the sameworld condition, children were asked to name the stickers (dog stickers as "dog" and cat stickers as "cat") as fast as possible by traveling along the path, pointing to each sticker, and naming it before moving on. In the oppositeworld condition, children were asked to travel on the same path but this time give each sticker the opposite name, that is, "cat" for the dog stickers and "dog" for the cat stickers. The story for the opposite-world condition was that it was very windy and the windmill was blown very hard, and eventually, everything else in the town was blown upside down. Children were asked to help the experimenter to re-attach the objects in an inverted position to show how everything looked after the wind storm. The cat and dog stickers, however, were fixed, and did not get inverted. Reversing the non-target items on the board was intended to help the children to understand that they would need to say the reverse labels. Half of the children in each setting were given the same-world condition first and the other half were given the opposite-world condition first. The number of errors and the difference in latencies (measured in seconds) between the same-world and opposite-world conditions was calculated for each child. 
Table 1 Mean score (and standard deviation) on background measures for the children in Canada and Hong Kong.

\begin{tabular}{lcc}
\hline \hline & Canada & Hong Kong \\
\hline PPVT-III (standardized score) & $101.60(10.3)$ & $94.65(13.5)$ \\
Print awareness & $3.44(1.5)$ & $4.27(1.9)$ \\
Cat-dog inhibition task (seconds) & & \\
$\quad$ Same-world & $29.27(8.6)$ & $23.73(4.9)$ \\
Opposite-world & $41.87(11.9)$ & $34.46(7.7)$ \\
Difference score & $12.60(7.6)$ & $10.73(6.3)$ \\
\hline \hline
\end{tabular}

\section{Moving word task}

The moving word task was adapted from previous studies (Bialystok, 1997; Bialystok and Martin, 2003). Two pictures are shown to the child and discussed, and then the experimenter presents a card that has the name of one of the pictures printed on it and tells the child what the word is. The child is asked: "What does the card say?", three times. The introductory question is asked after the card is placed under the picture it names. The incongruent question follows the disruption in which an interloper stuffed toy pushes the card to rest under the second picture. The congruent question is asked after the experimenter pretends to clean things up and moves the card back to its initial position under the named picture.

The moving word error is to assume that the meaning of the printed word is determined by the picture, so children who do not understand how print encodes meaning change their answer to the incongruent question, making the number of correct responses to this question the relevant score. The task was presented four times, each one using a different pair of pictures. The four pairs of pictures were claw-hoof, branch-tree, puppy-kitten, and forkspoon, with the printed word corresponding to the first in each pair, although the order in which the pictures were presented and their position on the left or the right side of the display was counterbalanced. The items in each pair were chosen to be semantically related in order to minimize the conceptual difference between the pictures. Two of the items (claw and branch) were represented by characters considered to be more iconic and the other two by characters considered to be arbitrary. The iconicity or arbitrariness of the characters was confirmed by adult judges who participated in a classification study (Luk and Bialystok, 2005). All the characters were written with the same number of strokes $(\mathrm{M}=3.5)$.

\section{Results}

The results of the background measures are reported in Table 1. There were no differences between children in the two settings for PPVT-III , $t=1.91$, n.s., or print awareness task, $t=-1.52$, n.s. A two-way ANOVA for reaction time in the cat-dog inhibition task showed that the Hong Kong children were faster than the Canadian children in both the same-world and the opposite-world conditions, $F(1,39)=7.38, p<.01$, and that children in both settings performed faster in the same-world than in the oppositeworld, $F(1,39)=112.26, p<.0001$, with no interaction, $F<1$. The important measure, however, is the increase in time needed to respond in the opposite-world, irrespective of the absolute speed in each condition. An analysis of these difference scores showed no difference between the groups, $F<1$.

The proportion correct in the moving word task for each of the three questions and two types of characters (for the Chinese children) are shown in Table 2. The distinction between iconic and arbitrary characters is irrelevant to the Canadian children, who see these words in printed English, but the distinction is maintained in the analyses to assure that there are no other inherent differences between these items. As expected, the classification by iconicity has no effect on performance for the Canadian children. The results from the introductory and congruent questions are reported in Table 2 but no analyses can be undertaken because the scores are at ceiling, hence have no variance. The data are reported to ensure that all the children understood the task and to provide a context in which to interpret the answers to the incongruent question.

A two-way ANOVA for place and iconicity on the proportion correct for the incongruent questions showed no effect for setting, $F=1.21$, n.s., iconicity, $F<1$, or their interaction, $F=1.18$, n.s. Therefore, the Canadian and Hong Kong children performed similarly on these questions. However, the Hong Kong children had a higher proportion of correct responses to the iconic trials than the Canadian children, even though the difference was not significant.

Table 2. Proportion correct (and standard deviation) in the moving word task by place for each question by iconicity of the Chinese character.

\begin{tabular}{|c|c|c|c|c|c|c|}
\hline \multirow{2}{*}{$\frac{\text { Question }}{\text { Materials }}$} & \multicolumn{2}{|c|}{ Introductory } & \multicolumn{2}{|c|}{ Incongruent } & \multicolumn{2}{|c|}{ Congruent } \\
\hline & Arbitrary & Iconic & Arbitrary & Iconic & Arbitrary & Iconic \\
\hline Canada & $1.00(0.0)$ & $1.00(0.0)$ & $0.63(.41)$ & $0.61(.34)$ & $0.96(.14)$ & $1.00(0.0)$ \\
\hline Hong Kong & $1.00(0.0)$ & $1.00(0.0)$ & $0.68(.40)$ & $0.76(.39)$ & $0.90(.23)$ & $0.92(.22)$ \\
\hline
\end{tabular}




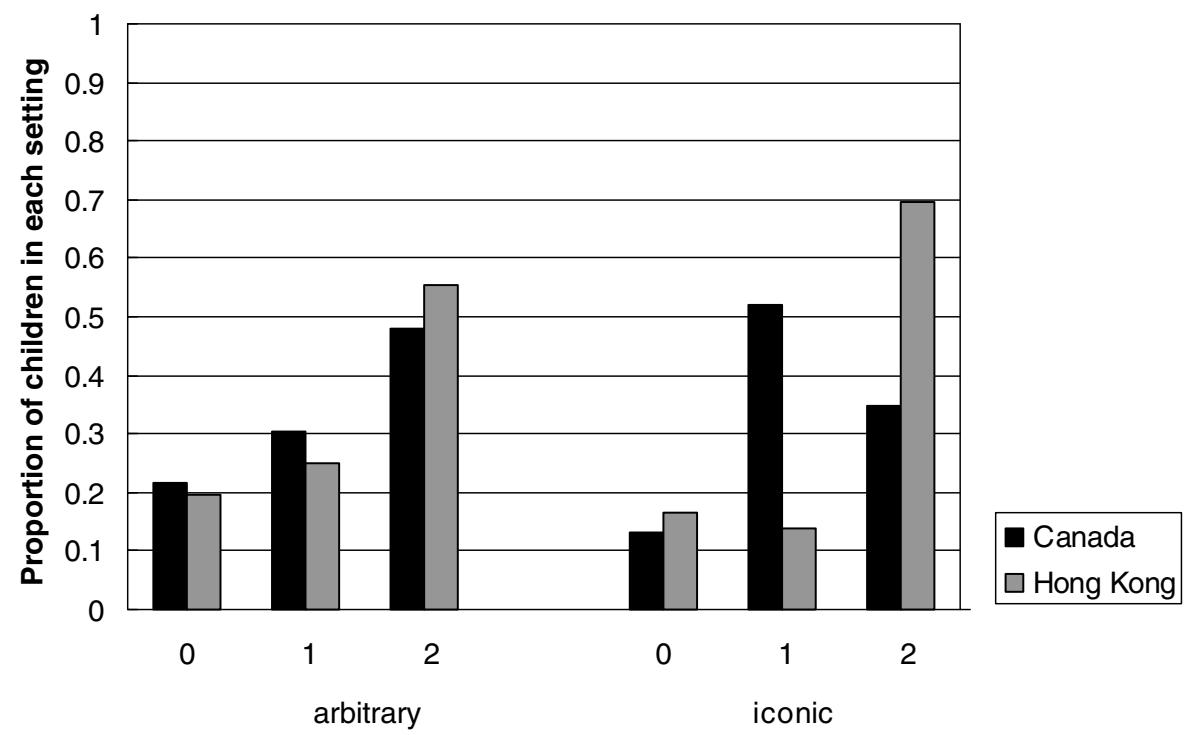

Performance in iconic and arbitrary items

Figure 1. Proportion of children at each performance level in each setting for iconic and arbitrary conditions of the incongruent questions.

Because the results were based on binary data in which children received either 1 or 0 over a set of four trials, the distribution of the responses was skewed. It is possible that the ANOVA failed to detect significant differences in part because of these characteristics of the distribution. Therefore, the data were further examined by means of non-parametric analyses to provide a more detailed description of the results. Wilcoxon rank-sum tests were used to compare children's performance on the incongruent questions for the iconic and arbitrary items. Figure 1 indicates the proportion of children in each setting who received a score of 0 (neither item correct), 1, or 2 for each of the arbitrary and iconic conditions. For the arbitrary items, the distribution of children obtaining the three possible scores is the same in the two settings, $Z=-.50$, n.s. For the iconic incongruent questions, however, the Hong Kong children performed significantly better than their Canadian counterparts, $Z=-1.99, p<.05$.

\section{Discussion}

Children in Canada and Hong Kong who were four years old and attending junior kindergarten performed the same on a set of background measures assessing vocabulary, awareness of print, and inhibitory control. The children in the two settings were embarking on literacy acquisition and learning to read in very different writing systems. None of the children could read independently, but all of them were becoming familiar with the forms of print used in their language and could identify those forms and recognize their own names in print. In spite of the considerable differences between the writing systems that each group of children was attempting to learn, all the children had to learn that the print they were learning is a symbolic representation that stands for spoken language and that it encodes meanings through the notational forms. All the children found the incongruent question of the moving word task to be more difficult than the other two questions and were misled by the possibility that the adjacent picture had some role in determining the meaning of the printed word or character. This was equally true for children learning to read in an alphabetic language and in a character language.

The primary reason for comparing concepts of print in children learning to read in these two systems is that the nature of the writing system might make this notion more or less accessible. Specifically, children learning to read in a character language might find it easier to accept that the written notation and not extraneous information indicates the meaning because the character is somehow more holistic, more meaningful, and in some cases, more iconic. Thus, this insight might be particularly easy to grasp for the iconic characters that bear some resemblance to the objects they signify. The results showed that the children in Hong Kong were no different from children in Canada for arbitrary characters, but iconic characters did give the Hong Kong children an additional boost, and their performance on these items was better than it was on arbitrary character trials and better than the Canadian children on all trials.

The interpretation of this pattern is that the acquisition of the insight about the symbolic function of print is 
equally important for children irrespective of the writing system that they are learning to read. However, children are given support for this insight if features of the writing system are more transparently related to the meanings they encode. Therefore, the assessment of their progress in understanding this concept shows more advanced insight for the easier items. Importantly, however, children learning to read in a character system cannot avoid the stage in which they need to master the cognitive insight about how print represents language, and their progress in mastering this idea is largely equivalent to that of children learning to read in an alphabetic language. Thus, in an important way, learning to read a character system presents the same cognitive challenges as learning to read an alphabetic system.

This interpretation is analogous to evidence from two other cognitive prerequisites in the acquisition of literacy. First, phonological awareness has long been recognized as one of the most crucial foundations for reading in an alphabetic system (partial review in Adams, 1990) but has more surprisingly found to underlie literacy acquisition in character languages as well (Ho and Bryant, 1997; Hanley, Tzeng and Huang, 1999; Shu, Anderson and Wu, 2000). However, the nature of the phonological unit that is most relevant and the accessibility of these units for children learning to read in different systems are not the same (McBride-Chang et al., 2004). Even within alphabetic languages, the phonological structure of some languages makes the identification of the relevant units more accessible, and children learning these languages profit by this facilitation. Cossu et al. (1988) found higher levels of competence in phonological awareness tasks for Italianspeaking children than for English-speaking children, presumably because of the greater phonological transparency of Italian, and Caravolas and Bruck (1993) reported that Czech-speaking children were better than Englishspeaking children in isolating consonants in clusters appearing in nonsense words, again reflecting differences in the phonological structure of the two languages. Similarly, Gonzalez and Garcia (1995) explored specific phonological properties of Spanish and their relation to phonological awareness and found different developmental patterns for each. Language-specific differences in phonemic sensitivity are pervasive, but the requirement for sensitivity to phonological structure is universal.

Second, the cognitive skills underlying decoding are essential for reading in all alphabetic languages, but the orthography of specific languages makes these skills differentially difficult to master. German-speaking children learning to read and spell performed a set of decoding tasks better than comparable English-speaking children (Frith, Wimmer and Landerl, 1998; Wimmer and Goswami, 1994). German is the more regular language than English, and German-speaking children were more advanced in their development of these skills.
The same pattern is found for the insight into the symbolic basis of print as a representational system. All children need to achieve this understanding, but the properties of some systems, and some features within those systems, make the insight more or less accessible. Therefore, for three essential cognitive prerequisites for literacy - phonological awareness, decoding, and concepts of print - there is a universal obligation for children to master these before they are able to read independently. The need for mastery is an overall similarity in the timetable, but there are modulations in the ease with specific aspects of the three cognitive prerequisites are achieved that are determined by the writing system and orthography.

This interpretation leans towards a universal conception of reading, but evidence from neuroimaging, reviewed above, shows significant distinctions between the neural activity associated with reading alphabetic and Asian languages. In the early stages, children's primary task is to establish the general cognitive mechanisms that enable reading to take place, and these abilities and their development are largely universal. Expertise, however, is characterized by more focal skills and more distinctive cortical activation patterns (Stiles et al., 2003). Therefore, as reading becomes more skilled, it takes on these characteristics of reduced and focused cortical activation. Furthermore, this specialization in reading as a function of different writing systems begins early - there is a strong correlation in bilingual children's decoding skills for two alphabetic languages but no relation in these skills for an alphabetic language and a character language (Bialystok, Luk and Kwan, 2005). It is not surprising, therefore, that readers who have mastered different systems will display somewhat different cortical signals that are specific to that skill. These signatures, however, must be considered in the context of other evidence, in particular, behavioral evidence from children learning to read, incorporating also their underlying universal cognitive commonality. Behavioral research that documents the incremental stages of reading acquisition remains crucial for interpreting the neuroimaging data and for understanding the processes involved in literacy acquisition for children across languages, across writing systems, and across cultures.

\section{References}

Adams, M. J. (1990). Beginning to read: Thinking and learning about print. Cambridge, MA: MIT Press.

Apperly, I. A. \& Robinson, E. J. (2002). Five-year-olds' handling of reference and description in the domains of language and mental representation. Journal of Experimental Child Psychology, 83, 53-75.

Bialystok, E. (1991). Letters, sounds, and symbols: Changes in children's understanding of written language. Applied Psycholinguistics, 12, 75-89. 
Bialystok, E. (1997). Effects of bilingualism and biliteracy on children's emerging concepts of print. Developmental Psychology, 33, 429-440.

Bialystok, E. (1999). Cognitive complexity and attentional control in the bilingual mind. Child Development, 70, 636-644.

Bialystok, E. (2000). Symbolic representation across domains in preschool children. Journal of Experimental Child Psychology, 76, 173-189.

Bialystok, E., Luk, G. \& Kwan, E. (2005). Bilingualism, biliteracy and learning to read: Interactions among languages and writing systems. Scientific Studies of Reading, 9, 4361.

Bialystok, E. \& Martin, M. M. (2003). Notation to symbol: Development in children's understanding of print. Journal of Experimental Child Psychology, 86, 223-243.

Bialystok, E., McBride-Chang, C. \& Luk, G. (2005). Bilingualism, language proficiency and learning to read in two writing systems. Journal of Educational Psychology, 97, 580-590.

Bialystok, E. \& Senman, L. (2004). Executive processes in appearance-reality tasks: The role of inhibition of attention and symbolic representation. Child Development, 7, 562579.

Bialystok, E., Shenfield, T. \& Codd, J. (2000). Languages, scripts, and the environment: Factors in developing concepts of print. Developmental Psychology, 36, 66-76.

Bolger, D. J., Perfetti, C. A. \& Schneider, W. (2005). Crosscultural effect on the brain revisited: Universal structures plus writing system variation. Human Brain Mapping, 25, 92-104.

Caravolas, M. \& Bruck, M. (1993). The effect of oral and written language input on children's phonological awareness: A cross-linguistic study. Journal of Experimental Child Psychology, 55, 1-30.

Chan, D. W., Ho, C. S.-H., Tsang, S., Lee, S. \& Chung, K. K. H. (2006). Exploring the reading-writing connection in Chinese children with dyslexia in Hong Kong. Reading and Writing, 19, 543-561.

Chen, Y., Fu, S., Iversen, S. D., Smith, S. M. \& Matthews, P. M. (2002). Testing for dual brain processing routes in reading: A direct contrast of Chinese character and pinyin reading using fMRI. Journal of Cognitive Neuroscience, 14, 10881098.

Chow, B. W., McBride-Chang, C. \& Burgess, S. (2005). Phonological processing skills and early reading abilities in Hong Kong Chinese kindergarteners learning to read English as a second language. Journal of Educational Psychology, 97, 81-87.

Collins, J. S. \& Robinson, E. J. (2005). Can one written word mean many things? Prereaders' assumptions about the stability of written words' meanings. Journal of Experimental Child Psychology, 90, 1-20.

Cossu, G., Shankweiler, D., Liberman, I. Y., Katz, L. \& Tola, G. (1988). Awareness of phonological segments and reading ability in Italian children. Applied Psycholinguistics, 9, 116.

Coulmas, F. (1991). The writing systems of the world. Malden, MA: Blackwell.

D'Angiulli, A., Siegel, L. S. \& Serra, E. (2001). The development of reading in English and Italian in bilingual children.Applied Psycholinguistics, 22, 479-507.
Dunn, L. M. \& Dunn, L. M. (1997). Peabody Picture Vocabulary Test-III. Circle Pines, MN: American Guidance Service.

Frith, U., Wimmer, H. \& Landerl, K. (1998). Differences in phonological recoding in German- and English-speaking children. Scientific Studies of Reading, 2, 31-54.

Gerstadt, C. L., Hong, Y. J. \& Diamond, A. (1994). The relationship between cognition and action: Performance of children $31 / 2-7$ years old on a stroop-like day-night test. Cognition, $53,129-153$.

Geva, E. \& Siegel, L. S. (2000). Orthographic and cognitive factors in the concurrent development of basic reading skills in two languages. Reading and Writing, 12, 1-30.

Geva, E., Wade-Woolley, L. \& Shany, M. (1993). The concurrent development of spelling and decoding in two different orthographies. Journal of Reading Behavior, 25, 383406.

Gonzalez, J. E. J. \& Garcia, C. R. H. (1995). Effects of word linguistic properties on phonological awareness in Spanish children. Journal of Educational Psychology, 87, 193-201.

Gottardo, A., Yan, B., Siegel, L. S. \& Wade-Woolley, L. (2001). Factors related to English reading performance in children with Chinese as a first language: More evidence of crosslanguage transfer of phonological processing. Journal of Educational Psychology, 93, 530-542.

Hanley, J. R., Tzeng, O. \& Huang, H. S. (1999). Learning to read Chinese. In M. Harris \& G. Hatano (eds.), Learning to read and write: A cross-linguistic perspective, pp. 173195. New York: Cambridge University Press.

Ho, C. S.-H. \& Bryant, P. (1997). Phonological skills are important in learning to read Chinese. Developmental Psychology, 33, 946-951.

Liu, Y. \& Perfetti, C. A. (2003). The time course of brain activity in reading English and Chinese: An ERP study of Chinese bilinguals. Human Brain Mapping, 18, 167-175.

Luk, G. \& Bialystok, E. (2005). How iconic are Chinese characters? Bilingualism: Language and Cognition, 8, 79-83.

Luk, G. \& Bialystok. E. (in press). Common and distinct cognitive bases for reading in English-Cantonese bilinguals. Applied Psycholinguistics.

McBride-Chang, C. (1995). What is phonological awareness? Journal of Educational Psychology, 87, 179-192.

McBride-Chang, C., Bialystok, E., Chong, K. K. Y. \& Li, Y. (2004). Levels of phonological awareness in three cultures. Journal of Experimental Child Psychology, 89, 93-111.

McBride-Chang, C., Shu, H., Zhou, A., Wat, C. P. \& Wagner, R. K. (2003). Morphological awareness uniquely predicts young children's Chinese character recognition. Journal of Educational Psychology, 95, 743-751.

Nunes, T., Bryant, P. \& Bindman, M. (1997). Morphological spelling strategies: Developmental stages and processes. Developmental Psychology, 33, 637-649.

Nunes, T., Bryant, P. \& Olsson, J. (2003). Learning morphological and phonological spelling rules: An intervention study. Scientific Studies of Reading, 7, 289-307.

Pu, Y., Liu, H.-L., Spinks, J. A., Mahankali, S., Xiong, J., Feng, C.-M. et al. (2001). Cerebral hemodynamic response in Chinese (first) and English (second) language processing revealed by event-related functional MRI. Magnetic Resonance Imaging, 19, 643-647.

Shu, H., Anderson, R. C. \& Wu, N. (2000). Phonetic awareness: Knowledge of orthography-phonology relationships in 
the character acquisition of Chinese children. Journal of Educational Psychology, 92, 56-62.

Stiles, J., Moses, P., Passarotti, A., Dick, F. K. \& Buxton, R. (2003). Exploring developmental change in the neural bases of higher cognitive functions: The promise of functional magnetic resonance imaging. Developmental Neuropsychology, 24, 641-668.

Tan, L. H., Laird, A. R., Li, K. \& Fox, P. T. (2005). Neuroanatomical correlates of phonological processing of Chinese characters and alphabetic words: A meta-analysis. Human Brain Mapping, 25, 83-91.

Tan, L. H., Liu, H.-L., Perfetti, C. A., Spinks, J. A., Fox, P. T. \& Gao, J.-H. (2001). The neural system underlying Chinese logograph reading. Neurolmage, 13, 836-846.

Tan, L. H., Spinks, J. A., Feng, C., Siok, W. T., Perfetti, C. A., Xiong, J. et al. (2003). Neural systems of second language reading are shaped by native language. Human Brain Mapping, 18, 158-166.
Tatsuno, Y. \& Sakai, K. L. (2005). Language-related activations in the left prefrontal regions are differentially modulated by age, proficiency, and task demands. The Journal of Neuroscience, 25, 1637-1644.

Wang, M., Cheng, C. \& Chen, S. (2006). Contribution of morphological awareness to Chinese-English biliteracy acquisition. Journal of Educational Psychology, 98, 542-553.

Wimmer, H. \& Goswami, U. (1994). The influence of orthographic consistency on reading development: Word recognition in English and German children. Cognition, 51, 91-103.

Xue, G., Dong, Q., Jin, Z., Zhang, L. \& Wang, Y. (2004). An fMRI study with semantic access in low proficiency second language learners. Neuroreport, 15, 791-796.

\section{Received 3 October 2006 \\ Revision received 12 February 2007 Accepted 21 February 2007}

